\title{
Opinions of Teachers' Students toward Teachers Who Smoked in Thailand: A Qualitative Study
}

\author{
Tharisara Chirasatienpon ${ }^{1}$, Phubate Napatpittayatorn ${ }^{1}$, Kanlapruk Polsorn ${ }^{2}$ \& Chomlak Kongart $^{3}$ \\ ${ }^{1}$ Major of Health education, Department of Physical Education, Faculty of Education, Kasetsart University, \\ Bangkok, Thailand \\ ${ }^{2}$ Major of Recreation, Department of Physical Education, Faculty of Education, Kasetsart University, Bangkok, \\ Thailand \\ ${ }^{3}$ Department of Thai Traditional Medicine, Faculty of Science, Ramkhamhaeng University, Bangkok, Thailand \\ Correspondence: Tharisara Chirasatienpon, Major of Health Education, Department of Physical education, \\ Faculty of Education, Kasetsart University, Bangkok, Thailand. Tel: 66-814-238-989. E-mail: fedutac@ku.ac.th; \\ tharisara89@gmail.com
}

Received: August 27, 2021

Accepted: September 28, $2021 \quad$ Online Published: October 6, 2021

doi:10.5539/hes.v11n4p59

URL: https://doi.org/10.5539/hes.v11n4p59

\begin{abstract}
The purpose of this qualitative research was to describe the opinions of teachers' students toward teachers who smoked in Thailand. The population was teachers' students $(\mathrm{N}=30)$ in their 1st-5th academic year of the Faculty of Education who participated based on purposive sampling according to eligibility criteria. The QDA Miner Lite program was used to analyze the qualitative data. The results indicated that the teachers' students understanding of a teacher was a person who conveys knowledge, experience and life skills in various fields for students both inside and outside the classroom and school. They should be a good person with knowledge and qualifications, displaying exemplary maturity in every way and be a role model. Like a family that gives love and keeps training and teaching in the right way. A teacher should be a good adviser and listen to problems. The ideal teacher must love to teach proficiently and be knowledgeable in what is being taught, allowing students to understand various forms of knowledge and be current. Smoking also affects being a teachers' students, in terms of inappropriateness and was not suitable for future teachers as it could affect the image of the organization. It also has harmful effect on health. A method that is likely to help prevent smoking among teachers' students and teachers is to create awareness through training and organizing various projects such as establishing a smoking cessation treatment center and campaigning for ways to replace smoking or to refrain from smoking.
\end{abstract}

Keywords: teachers' students, opinion, teacher, smoking

\section{Introduction}

Smoking is a negative behavior that affects to physical, mental and social health. Smoking is risky behavior that leads to chronic non-communicable diseases (NCDs) such as respiratory disease, diabetes, high blood pressure and increased severity of cardiovascular disease (Masood et al., 2020). Furthermore, it increases the risks of myocardial infarction and can develop into chronic non-communicable diseases with age (Gao et al., 2017). Nowadays, people tend to start smoking at a younger age. However, smoking is a major Thai public health problem as it is often the first drug that young people become addicted to and it is also a medium that can lead to other more serious drugs. Starting to smoke at a young age can result in a highly addicted adult who finds it difficult to quit smoking and is more likely to get sick than someone who only started smoking as an adult (Kraturerk et al., 2020). Smoking has effects on families, communities, society and the nation including wasting money, loss of a loved one through smoking-related illness, loss of manpower in the country's development, personal suffering from illness and decreased quality of life (Madanhire and Mbohwa (2019).

Survey data from the National Statistical Office Thailand (2017) on smoking habits of the Thai population in 2017, indicated that for the population aged 15 years and over (55.9 million people), from these, 0.7 million $(19.1 \%)$ were smokers. This data was divided into 9.4 million regular smokers $(16.8 \%)$ and 1.3 million (2.3\%) infrequent smokers in the age group 25-44 years, with the highest smoking rate (21.9\%) in the age group 20-24 years $(20.7 \%)$, followed by the age group $45-59$ years $(19.1 \%)$, the elderly (aged 60 years and over $(14.4 \%)$ and 
youth (15-19 years) with the lowest low smoking rate (9.7\%). Today, the smoking habits of adolescents are influenced by various factors both internal and external involving the environment surrounding the adolescent including friends, family, school and society. School is a very important place to prevent youths taking up smoking because it is a place with teachers who have roles and duties in polishing, training and teaching students to be knowledgeable, capable and have the good characteristics desired by society (Kim and Kim, 2018). The current role of teachers in today's society has changed according to economic, political, social and cultural forces. Therefore, professional teaching must possess the spirit of being a teacher. Kunarak (2018) concluded that a professional teacher needed to have the following characteristics: 1) to teach with clarity; 2) to strive to teach with enthusiasm and be a good role model; 3) to always active and willing to understand the learners; 4) to be a creative and good communication; 5) to have a good physical health and mental health; 6) to promote students in the right way with life goals. Empathy to students with patience; 7) to be responsible as a guardian; 8) to be able to work systematically with new learning and new teaching method. Great storyteller and summarizer; 9) to be an educator; 10) to always self-development. Parent characteristics personality; 11) to inspire initiative in the school and know individual differences; 12) to prevent problems and promote well-being through student's health by providing the knowledge; 13) to persuade students to teach; 14) to be trustworthy, be empathetic and to utilize any special abilities; and 15) high self-confidence and excellence in theory and practice.

The study by Ozbas et al., (2018) on "Behavior and attitudes towards smoking among teachers in Turkey" found that the smoked teachers became aware of the harmful effect for their health but they had no intention to change their behavior and attitudes against smoking. In addition to this behavior, they continued smoking because they enjoyed the biological effects of smoking and disregarded its harmful effects. In 2019, the Ministry of Education Thailand, Thai Health Promotion Foundation, Office of the Non-Alcoholic Organization Network, along with the Office of the Basic Education Commission (Kham-Por-Son School Network and The teacher's network without all vices) promoted the awards "Good teacher without all vices" (Generation 9) and "Good school without all vices" (Generation 4) for academic year 2019, on the occasion of National Teacher's Day 2019, the committees were selected qualified educational personnel under the criteria "free from all kinds of alcoholic beverages, cigarettes and gambling along with safe environment for their students and communities". In this ceremony, the teachers were set aspirations to be a good teacher without any vices with jointly announcing their intentions and proposals for educational management to prevent and solve problems associated with alcohol, cigarettes, and mischief to the country (Siamrath Online, 2020). The "Good teacher without all vices" project progressed into its 10th year in 2020 with the goal of Thai teachers being a role model for students to grow up in a society living free from all vices, also to help students and the people around them to be free from all vices specifically by focusing on abstaining from all kinds of alcohol, cigarettes and gambling. In 2021, 63,512 teachers identified themselves as good teachers without any vices through registration and enrollment via the worldwide web link "Kham-Por-Son School Network.com" and 322 teachers were selected as role models to receive an award (WorkpointTODAY online, 2021).

A teacher acting as a good role model affects students' behavior in promoting avoiding smoking and other types of drug addiction or all vices. Therefore, the researcher wanted to identify and analyze the opinions of teachers' students towards teachers who smoked with the goal of preventing smoking uptake and to reduce subsequent important problems to the country by finding the ideal teacher characteristics that would encourage teachers' students to become good teacher in the future.

\section{Methodology}

\subsection{Study Design and Setting}

This study involved qualitative research. Data were collected from February 1 to February 28, 2021 at Faculty of Education Kasetsart University, Bangkok, Thailand. Data were collected from in-depth interviews using an online program that lasted approximately 20-30 minutes and the participants were compensated with THB 300 for their time. The research objective was to describe the opinions of students towards their teachers who smoked.

\subsection{Study Population and Sampling}

The participants were students in academic year 1-5 in the Department of Physical Education, Faculty of Education, Kasetsart University. The sampling process selected participants according to the specified qualifications. Prior to any data collection, informed consent was obtained from all participants and they were allowed to withdraw from the study at any point without any penalty. The interview questions related to their opinions of students towards teachers who smoked. There were 30 participants in the research project until the end of the project. Most of the participants were female (63.3\%) and 33.3\% of the participants were aged 21 
years, with most participants (33.3\%) being in their $3^{\text {rd }}$ academic year in the Faculty of Education. The general characteristics of the participant are listed in Table 1.

Table 1. Statistics for participants based on general characteristics $(n=30)$

\begin{tabular}{llll}
\hline Variable & Category & N & Percentage \\
\hline Gender & Male & 11 & 36.7 \\
& Female & 19 & 63.3 \\
Age (years) & 18 & 3 & 10.0 \\
& 19 & 4 & 13.3 \\
& 20 & 7 & 23.3 \\
& 21 & 10 & 33.3 \\
& 22 & 3 & 10.0 \\
Academic year & 23 & 3 & 10.0 \\
& 1 & 4 & 13.3 \\
& 2 & 9 & 30.0 \\
& 3 & 10 & 33.3 \\
& 4 & 4 & 13.3 \\
& 5 & 3 & 10.0 \\
\hline
\end{tabular}

\subsection{Data Collection Tools}

1. The demographic data questionnaire consisted of gender, age and academic year level.

2. In-depth interview questionnaires were created to gauge the opinions of the participants toward teachers who smoked based on 5 questions: 1) What is a teacher, based on the teachers' students understanding? 2) What is an ideal teacher like? 3) What do you think of teachers who smoke? 4) What effect does smoking have on being a teachers' students? 5) Is there any method that might help prevent smoking among teachers' students?

\subsection{Data Collection}

Data collection took place for online interview via the Zoom program at Kasetsart University, Bang Khen campus. Each participant was interviewed at different times, at the convenience of the research participants. The interview started by building a relationship in a friendly atmosphere. The participants were asked to answer the demographic data questionnaire via a Google form. After that, an in-depth interview was conducted to record each participant's thoughts on the 5 questions detailed above. There was a single in-depth interview with each participant that took approximately $20-30$ minutes per participant.

After the interview, the researchers examined the quality and reliability of the data according to the guidelines from Lincharearn (2012) as follows: 1) all data were recorded and presented in a descriptive form to illustrate all aspects in detail after the completion of each data collection event; 2) co-researchers help to record, review, verify data, analyze preliminary data that the researchers recorded and analyze and cross-check all data, to ensure the data recording was reliable; 3 ) the data triangulation method was used to check whether the data obtained by the researcher was correct or not by comparing the observations of the participants with the interview data of the researchers, and by comparing the same data from multiple informants in the same group.

\subsection{Data Analysis}

1. Quantitative data: Demographic data were analyzed using the descriptive statistics of frequency and percentage.

2. Qualitative data: The information obtained from the in-depth interviews was transcribed and translated into Thai. A software package was used to analyze qualitative research data (CAQDAS). The researcher used the QDA Miner Lite program to analyze the qualitative research data. This tool was efficient for data analysis, was convenient to use, was quick and provided good accuracy (Joungtrakul, 2019). The researcher used qualitative data analysis techniques by analyzing the data by classification (typological analysis) and organizing the data based on the criteria established by the researcher. Classification or grouping of this data classified the data at the micro level using keyword analysis and taxonomic analysis. Keyword analysis involved by grouping words, so the grouping of a set of words together was based on the relationship characteristics of each word used to group them (Lincharoen, 2012). The researcher divided the data analysis process based on general content analysis as described by Kuckartz (2019) into 8 steps: (1) prepare the data; (2) define the unit of analysis; (3) develop categories and a coding scheme; (4) test the coding scheme on a sample of text; (5) code all text; (6) assess the 
coding consistency; (7) draw conclusions from the coded data; and (8) report the methods and findings.

\subsection{Ethical Consideration}

In this research, the researcher determined the rights of the sample based on clear inclusion and exclusion criteria. Each participant in the sample group signed a consent to participate in the research project before starting the research. This research project was submitted for ethics review by the Human Research Ethics Committee. Kasetsart University Bangkhen and was approved to proceed (number KURDI code no. COE63/238. on November 25, 2020). Due to the COVID-19 epidemic, an online interview format was used via the Zoom program in a quiet place and secluded setting. Each participant was able to opt-out of participation in the study without any impact on their studies. No data were recorded on name, address and identity data. The tape recordings will be destroyed once the research report has been published successfully.

\section{Results}

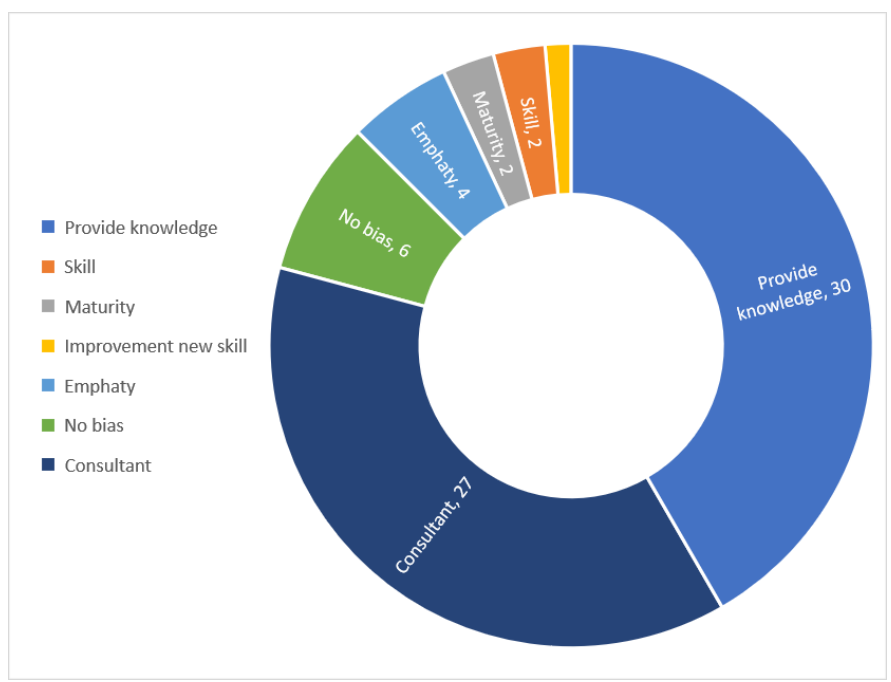

Figure 1. Summary of responses to question 1) What is a teacher, based on the teachers' students understanding?

\section{Question 1) What is a teacher, based on the teachers' students understanding?}

The informants reflected on what they considered a teacher to be with sub-issues and details.

1.1 A teacher is a person who transfers knowledge to students (30 out of 30 participants). Examples provided were:

"Teachers are educators and keep teaching, to develop students well."

"Teacher is someone who guides and teaches both in terms of knowledge and life."

"Teachers are educators, who keep an understanding of various subjects. Who likes a mold that develops learners to reach their dreams, have knowledge and develop themselves to survive in the future."

1.2 Teachers act as a consultant by helping, suggesting and solving problems (27 out of 30 participants). Examples provided were:

"Teacher is someone who can solve problems for students and be a mentor for students' livelihoods."

"Teachers are trustworthy. Being a mentor to students, able to teach and give advice on both learning and life."

"Teachers are the ones who teach student both about learning and life. Students are comfortable and able to talk about anything. Always give advice and help in every matter. Understand what the environment of the student is going through." 


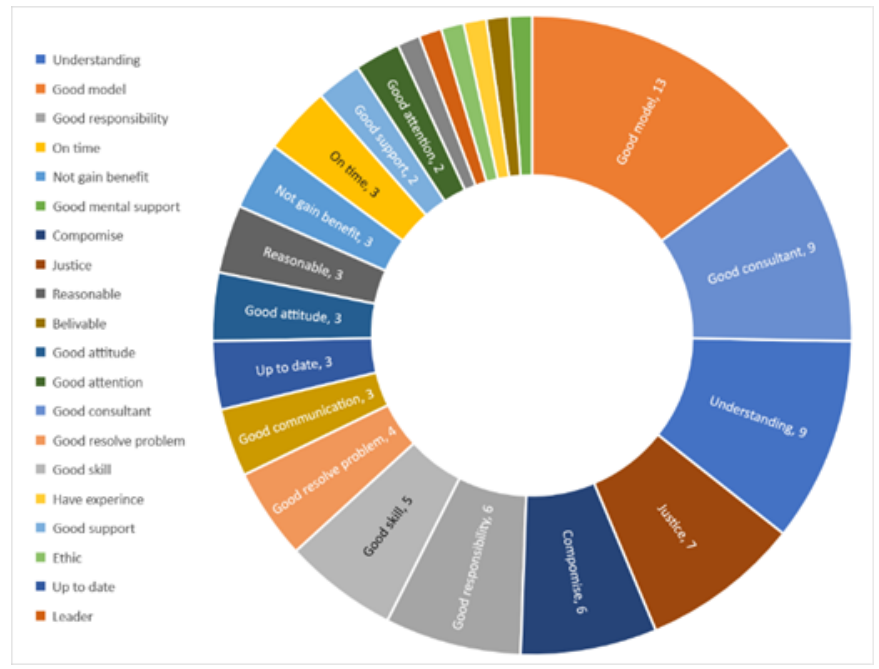

Figure 2. Summary of responses to question 2) What is an ideal teacher like?

\section{Question 2) 2) What is an ideal teacher like?}

The informants reflected on what their ideal teacher looked like with sub-issues.

2.1 The ideal teacher is someone who provides a good role model for students (13 out of 30 participants). Examples provided were:

"Be a good role model both internally and externally"

"Reliability is a good role model for students. Be considerate and considerate to student."

"Who is a respected person, good person to society and has a kind heart."

2.2 The ideal teacher is someone who understands students, can be a good consultant and can solve problems (22 out of 30 participants). Examples provided were:

"Friendly with students like our second parents. Always ready to listen to us and help us solve any problems."

"Understanding student, listening to problems sincerely with love and affection"

"Understanding students, knowing the problems of the students and ready to reach out to help."

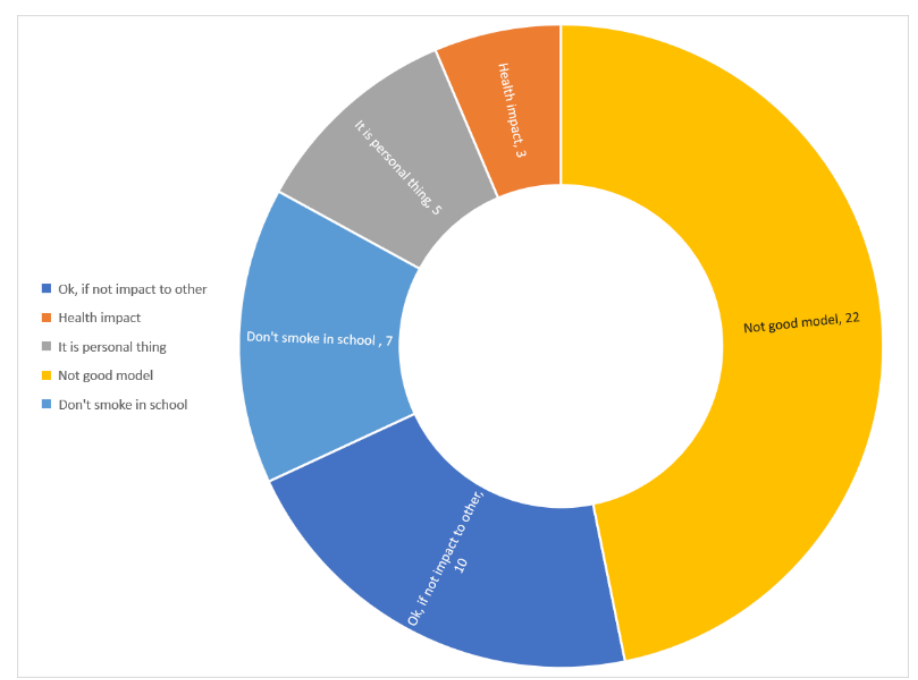

Figure 3. Summary of the responses to question 3) What do you think of teachers who smoke? 


\section{Question 3) What do you think of teachers who smoke?}

The informants reflected on what they thought of the teachers who smoked with sub-issues.

3.1 What do you think about teachers who smoke? It's a negative role model for students (22 out of 30 participants). Examples provided were:

"It is not appropriate because it will be a negative role model for students. In terms of personality, respectable credibility, health, work and teaching. On the other hand, smokers are not really bad people because I think it's personal rights, reasons or personal preference. If they don't do a negative things or cause of trouble to others, there's no problem. However, they must do not smoking cause effect to students both inside and outside the school, especially teachers in the field of teaching health."

"Be a negative role model for students. Looks like a disrespectful teacher will cause student to start asking questions about teachers who are the currently smoker. Why can't a student smoke some?"

"I think it's a negative role model. If students see them; students may act accordingly. Lack of credibility."

3.2 It's a personal right but I don't want them to smoke in school (7 out of 30 participants). Examples provided were:

"It's a personal preference but they don't smoke in school for students to see because teacher should be a good role model for students."

"If the teacher smokes, please do not expose smoking behavior to students to see, it's okay for me. If smoking behavior expose to student, it might be a bad role model for students to follow because students will think that teachers can smoke and students can smoke too. However, it also depends on the student's mindset whether to follow or not."

"It's okay to smoke outside of school but if they smoking at school and expose to students, I do not agree. Have other teachers admonish them to behave like this."

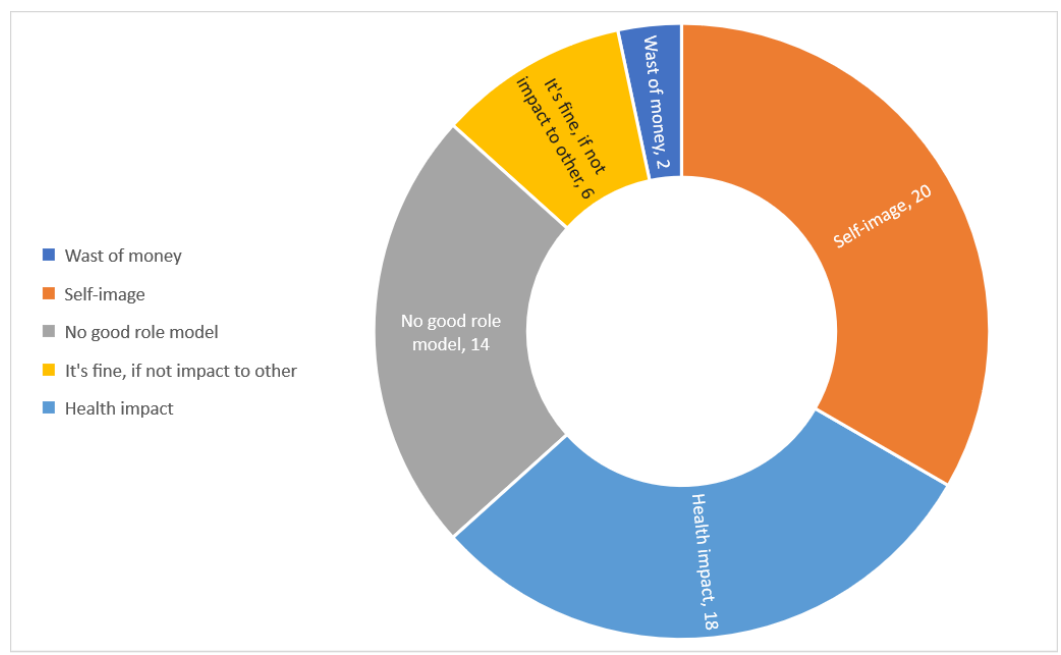

Figure 4. Summary of the response to question 4) What effect does smoking have on being a teachers' students?

\section{Question 4) What effect does smoking have on being a teachers' students?}

The informants reflected on how smoking affected being a teachers' students with sub-issues and details.

4.1 What effect does smoking have on being a teachers' students? It affects personality and image (20 out of 30 participants). Examples provided were:

"It has an impact on the image of the teacher. Students do not want to get close because the smell of cigarette smell on the clothes, according to the teacher's body, causes a bad image."

"It affects the daily life of being a teachers' students, for example, the personality will look bad or it will be the subject of an unpleasant smell. It can cause varies problems for people around them."

"It makes the personality not good, such as black gums, bad breath, body odor caused by smoking which also has a negative effect on the people around them which teachers' students should not do."

4.2 What effect does smoking have on being a teachers' students? (18 out of 30 participants). Examples provided 
were:

"It affects health. Smoking makes it easier than usual to get sick. It's a waste of time preparing for teaching experience when smoking."

"A negative effect on their own body and those around them who are exposed to cigarette smoke affecting personality. People around them have negative thoughts and attitudes towards teachers' students who smoke."

"Reduce health, wellness and efficiency of life"

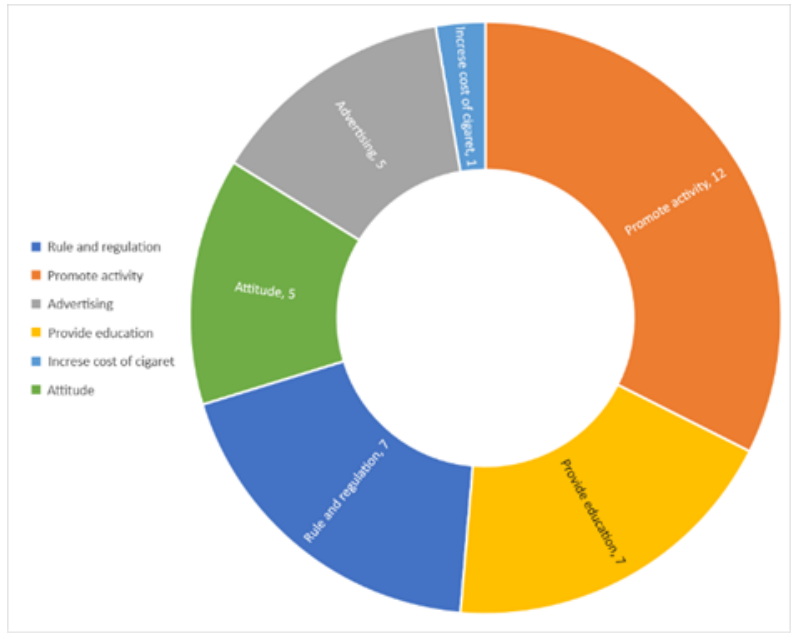

Figure 5. Is there any method that might help prevent smoking among teachers' students?

\section{Question 5) Is there any method that might help prevent smoking among teachers' students?}

The informants reflected on what methods were likely to help prevent smoking among teachers' students with sub- issues and details.

5.1 Is there any method that is likely to help prevent smoking among teachers' students? Educating and organizing activities to campaign against smoking (19 out of 30 participants). Examples provided were:

"Organized activities to educate the methods and guidelines for preventing smoking and activities to dissolve behaviors that tell disadvantages. The seriousness of cigarettes, both for smokers and those exposed to secondhand smoke.

"Organized a campaign to educate about the negative effects of cigarettes that affect the body and people around them?"

"Organized a campaign to educate about smoking prevention and organize activities that take advantage of free time such as sports, various physical activities."

5.2 Is there any method that is likely to help prevent smoking among teachers' students? Raising awareness and awareness of smoking prevention (12 out of 30 participants). Examples provided were:

"Let's them aware of the dangers of smoking by set up the campaign to create a notice board in the university."

"Cultivate awareness of the dangers of smoking to themself and others, should always remember that we must be a good role model for students both in behavior and health."

"Encourage them to aware of the dangers of smoking for health and realizes in their future career to be a good teacher and good model."

\section{Discussion}

\subsection{Discussion on Question (1)}

The opinions of teachers' students towards teachers who smoked raised the following points. Teachers (based on the understanding of teachers' students) are people who transfer knowledge, experience and life skills in various fields to students both inside and outside the school. A teacher should be a good person with knowledge, qualifications, maturity, treat you like family or a second parent that gives love, provides training and teaching of 
the right way to do things, is a good adviser, listens to problems, compromise, helps solve problems the right way, stays available without coercion or violence, truly understand students and has a positive attitude toward students. A teacher can recommend and support what students are interested in the right way and can develop students to live in society happily with knowledge and a quality future. It can be said that teachers are everything around a student from which the student can learn directly or indirectly. These responses were consistent with the research of Phra Mongkhon Sutakom (Sitthichai Atithammo, 2017) who stated that "teacher is a second parent" because teachers have roles and responsibilities for teaching, training, caring and developing students from kindergarten until graduation. Normally, students are at school for 6-8 hours, when parents are working. Therefore, the currently role of teachers has more influence for students on both taking care and training in terms of educating, developing skills and abilities, giving love, warmth and intimacy as a "second parent".

\subsection{Discussion on Question (2)}

The ideal teacher according to opinion of the teachers' students must love to teach, be knowledgeable, expertise and know about what they teach student and understand a variety of ways to do that, which is consistent with Jamjuree, (2017) who stated that "a teacher is a key mechanism which drives the quality of education". So, the teacher should be respectful, trustworthy, on time, dress and act well by being a leader. A teacher should be a good role model both internally and externally, like parents, being ethical, kind, compassionate, loving and caring, responsible, punctual, patient, diligent, optimistic, have a positive attitude and be smiling and friendly. The teacher should not be fair and impartial to students. A teacher is honest and does not profit from students, but encourages and uses rational discussions rather than blaming and does not block students' thoughts, while listening to students and others and understanding students in every aspect, by paying attention and not overlooking small problems, helping and solving problems with peace of mind and can talk about anything, give good advice and support in every matter so that the students can enjoy studying. These results are consistent with the research by Chalothon et al., (2020) who stated that good teachers must be punctual, understand children, use a transmission strategy consisting of showing good examples and introducing good things to students. It is also consistent with the research of Athiratpanya et al., (2018) who stated that there are 5 components to the ideal teacher: 1) being a teacher; 2) a person of learning; 3 ) morality; 4) an intellectual way of creating knowledge; and 5) a love of the teaching profession. On the one hand, from the research results of Nammuang (2017) the ideal teacher had: 1) physical aspects, for example, teachers must dress appropriately, manners, posing, use of words, various gestures and must be neat; 2) emotional aspects such as knowing how to control emotions well, high maturity having a sense of humor responsibility punctuality, diligence and generosity; 3 ) social aspects such as leadership, human relations and adaptability; 4) intellectual aspects such as creativity, tact, observing including knowing how to apply the seven principles of "Sappuris Dhamma" and good teaching characteristics. The current research results can be divided into 2 types; 1 ) Teaching preparation, where teachers must know how to analyze the curriculum. The teaching and learning process includes readiness in the classroom, setting good content links that meet the learning needs of the learners. Teachers need to develop themselves all the time involving both external and internal personality as well as adopting modern teaching styles relevant to current events in society. In addition, Prasarntri (2012) described the student model as a teacher, where such students must have competencies in 2 aspects. The first is knowledge consisting of: 1) the importance of the teaching profession, roles, duties, and tasks of teachers, on training and teaching and transferring knowledge; 2) the development of the teaching profession 3) the characteristics of a good teacher are good teaching; 4) the creation of a positive attitude towards the teaching profession, including building knowledges and understanding of the content being taught and creating a positive attitude towards the teacher's profession; 5) strengthening the potential and competence of a teacher, including education and training in teacher-related subjects; 6) being a person of learning and leadership in academic contexts, including enthusiasm and interest in learning; 7) having professional standards of knowledge include language and technology for teachers; 8) ethics, including self-discipline; 9) awareness of the legislation related to education, such as the National Education Act. The second aspect is competency consisting of: 1) love, kindness towards learners (helping and supporting); 2) patience and responsibility including with students' problems and their behavior and these responsibilities include self-responsibility; 3) being a person of learning and academic leadership; 4) having a vision, including creating a vision; 5) faith in the teaching profession, including support operations of a professional teacher organization; 6) complying with the code of conduct, with the professional ethics of teachers being ethics to oneself.

\subsection{Discussion on Question (3)}

What do you think of teachers who smoke? The teachers' students considered such behavior as inappropriate because it provided a negative role model for students in terms of personality, reliability, respect, health, work 
and teaching, even though smokers were not inherently bad people. Rather this was about rights, reasons or personal preferences so teachers must not smoke in the both inside and outside the school, especially teachers in the field of teaching health. These results were consistent with the research of Kunarak (2018) found that professional teachers must have the spirit of being a teacher and should have the following characteristics: 1) to teach with clarity; 2) to strive to teach with enthusiasm and be a good role model; 3) to always active and willing to understand the learners; 4) to be a creative and good communication; 5) to have a good physical health and mental health; 6) to promote students in the right way with life goals. Empathy to students with patience; 7) to be responsible as a guardian; 8) to be able to work systematically with new learning and new teaching method. Great storyteller and summarizer; 9) to be an educator; 10) to always self-development. Parent characteristics personality; 11) to inspire initiative in the school and know individual differences; 12) to prevent problems and promote well-being through student's health by providing the knowledge; 13) to persuade students to teach; 14) to be trustworthy, be empathetic and to utilize any special abilities; and 15) high self-confidence and excellence in theory and practice. However, smoking initiation is a key component of an important can cause diseases in people who are close, especially children. This was also consistent with the findings of Csákányi et al., (2012) were found a correlation between environmental tobacco smoke (ETS) and acute otitis media (AOM) with other adverse auditory outcomes with ears, throat and nose. By the way, young children are especially vulnerable to the poisons in secondhand smoke (Walton et al., 2020).

\subsection{Discussion on Question (4)}

What effect does smoking have on being a teachers' students? This was considered to be extremely inappropriate because it was contrary to being a good role model for students. It could affect the image of the organization and also has a negative effect on health. Life efficiency and personality, such as having an unpleasant smell, may result for those around smokers and those who don't like the smell of cigarettes will not want to get close. Smoking can affect external personality such as bad breath, black lips and gums, teeth having plaque from smoking and periodontal disease. This was consistent with the study of Prai-ngam et al., (2019) who described the negative effects that can occur with a smoker, especially on the oral health of people who receive dental services, such as cigarette odor, cigarette stains on teeth, periodontal disease and oral lesions, thus motivating dentists to give advice on quitting smoking.

\subsection{Discussion on Question (5)}

Is there any method that might help prevent smoking among teachers' students? Suggestions provided included: 1) creating awareness through training, various projects, providing a smoking cessation treatment center and campaigning for ways to replace smoking or refraining from smoking, such as public relations posters or making a short film about the effects of smoking; 2) setting up recreation, leisure and sports activities. The activities could be changed the behavior by presenting the disadvantages and seriousness of smoking to both smokers and those exposed to secondhand smoke; and 3) providing challenging activity such as quitting smoking within 3-5 days. Requiring strict rule in schools to all parties. The governments need to adopt a comprehensive approach to tobacco control, make reducing smoking. This was in accordance with the campaign of the "ideal teacher", who free from vices, also to help students and the people around them to be free from vices specifically by focusing on abstaining from all kinds of alcohol, cigarettes and gambling. This is an extremely important project as it offers an award that does not involve competition with anyone but oneself and provides a satisfying victory if achieved. Siamrath Online (2020) stated that creating a smoke-free school through banning both teachers and students from smoking in schools would create a smoke-free environment for youth. For example, a school in Finland found that students in schools with a smoking restrict will smoke less than students attending schools without this rule (Action on Smoking and Health Foundation Thailand, 2016). Research by Yeephu (2018) discussed learning activities to reduce and quit smoking behavior for children and adolescent drug addiction patients by applying the results of research in Phase 1, where important emphasis on the principles was placed on children and adolescent drug patients to control their behavior through self-guidance. This was used as a determinant in the formulation of learning activities to reduce and quit smoking behavior, consisting of 8 activities: 1) building relationships and setting goals for smoking control; 2) identifying and controlling the triggers that lead to smoking; 3) rejection skills; 4) coping skills; 5) avoiding a relapse; 6) self-reward planning when smoking control goals can be achieved; 7) timing and controlling the amount of smoking; and 8) having a smoking behavior control plan by having a reduction score regarding quitting smoking behavior by children and adolescent drug patients after participating in the activity being higher than before participating in the activity.

\section{Conclusion}

Most participants agreed that ideal teachers should not smoke because it generates a negative memory. 
Furthermore, students tend to imitate their smoking behavior from those around them. The teacher is a person who is close to the students, both inside and outside the classroom. In addition, the various negative effects of teachers who smoke include negative personality, lack of credibility with colleagues and students, as well as having harmful effects on teacher's health from various diseases such as emphysema, lung cancer, gum disease and lung disease, including affecting the students and people around the teacher who are exposed to secondhand smoke as well. The results of this research demonstrated the perception of teachers' students of the various dangers that occur with smoking behavior both in terms of previous experience and foreseeing the future concerning smoking behavior among teachers. Brainstorming on options for smoking prevention among teachers' students and a health education program or activities will create awareness and improve the effectiveness of smoking prevention as well.

\section{Acknowledgement}

This study was funded by Kasetsart University, Bangkok, Thailand.

\section{Author's Contributions}

Tharisara Chirasatienpon: Authorship and corresponding Author; Main idea, making framework, and revisions.

Kanlapruk Polsorn: Co-author, editorial assistants

Phubate Napatpittayatorn: Editorial assistants

Chomlak Kongart: Editorial assistants

\section{Competing Interests Statement}

The authors declare that there are no competing or potential conflicts of interest.

\section{Reference}

Action on Smoking and Health Foundation Thailand. (2016). How to smoke free school. Retrieved from http://www.ashthailand.or.th/th/youth_page.php?id=1457

Athiratpanya, J., Niamhom, W., Soopanyo, W., \& Srisuantang, S. (2018). Pathway of teachers development in basic education toward good teachers. Veridian E Journal, Silpakorn University, 11(1), 1403-1418. Retrieved from https://he02.tci-thaijo.org/index.php/Veridian-E-Journal/article/view/119925/91633

Chalothorn, P., Prateep Jinnge, P., \& Narisara Peungposop, N. (2020). The socialization of spirituality in teachers: A case study of teachers at faculty of Education in Rajabhat University in the northeast. NRRU Community Research Journal, 14(1), 110-122. Retrieved from https://so04.tci-thaijo.org/index.php/NRRU/article/view/240087/163800

Csákányi, Z., Czinner, A., Spangler, J., Rogers, T., \& Katona, G. (2012). Relationship of environmental tobacco smoke to otitis media (OM) in children. Int J Pediatr Otorhinolaryngol, 76(7), 989-93. https://doi.org/10.1016/j.ijporl.2012.03.017

Gao, K., Shi, X., \& Wang, W. (2017). The life-course impact of smoking on hypertension, myocardial infarction and respiratory diseases. Scientific Reports, 7(1), 4330. https://doi.org/10.1038/s41598-017-04552-5

Jamjuree, D. (2017). Teacher Training and Development in Thailand. Journal of Research and Curriculum Development, 7(2), 7-19. Retrieved from https://so03.tci-thaijo.org/index.php/jrcd/article/view/115560/89286

Joungtrakul, J. (2019). Qualitative research: Choosing and appropriate computer software program for data analysis in qualitative research. 6(2), 148-160. Retrieved from http://www.journal.rmutt.ac.th/index.php/mmr-vol1/article/view/1695

Kim, D. J., \& Kim, S. J. (2018). Impact of nearby smoking on adolescent smoking behavior in Korea. Medicine, 97(45), 1-7. https://doi.org/10.1097/MD.0000000000013125

Kunarak, K. (2018). On Becoming a Professional Teacher. Academic Journal Bangkok Thonburi University, 7(2), 1-7. Retrieved from http://center.bkkthon.ac.th/journal/upload/doc/spit/21/files/1-7.pdf

Kuckartz, U. (2019). Qualitative Text Analysis: A Systematic Approach. https://doi.org/10.1007/978-3-030-15636-7_8

Kraturerk, W., Benjakul, S., Kengganpanich, M., \& Kengganpanich T. (2020). The Effects of the Smoking Cessation Program applying the Social Cognitive Theory among Naval Rating Students at Naval Education Department, Royal Thai Navy. Royal Thai Navy Medical Journal, 47(2). 317-339. Retrieved from 
https://he01.tci-thaijo.org/index.php/nmdjournal/article/view/244520/166087

Lincharearn, A. (2012). Qualitative Data Analysis Techniques. Journal of Educational Measurement Mahasarakham University, 17(1), 17-29. Retrieved from

https://so02.tci-thaijo.org/index.php/jemmsu/article/view/149164/109532

Madanhire, I., \& Mbohwa, C. (2019). Impact of Smoking in a Tobacco-Growing Developing Country: A Review. Smoking - Prevention, Cessation and Health Effects. https://doi.org/10.5772/intechopen.85959

Masood, S., Cappelli, C., Li, Y., Tanenbaum, H., Chou, C. P., Spruijt-Metz, D., Palmer, P. H., Johnson, C. A., \& Xie, B. (2015). Cigarette smoking is associated with unhealthy patterns of food consumption, physical activity, sleep impairment, and alcohol drinking in Chinese male adults. International journal of public health, 60(8), 891-899. https://doi.org/10.1007/s00038-015-0730-7

Nammuang, C. (2017). Teacher Personality and Good Teaching Characteristics. Journal of Saengkhomkham Buddhist studies, 2(1), 55-64. Retrieved from https://so02.tci-thaijo.org/index.php/jsbs/article/view/242569/164595

National Statistical Office Thailand. (2017). National Statistical Office Thailand revealing the results of Smoking Behavior Survey in 2017. Retrieved from http://www.nso.go.th/sites/2014/Pages/News/2561/N31-08-61-1.aspx

Ozbas, S., Onur, R., \& Alkan, M. A. (2018). Behavior and attitudes towards smoking among teachers in Turkey. Journal of Public Health. https://doi.org/10.1007/s10389-018-0961-1

Phra Mongkhon Sutakom (Sitthichai Atithammo). (2017). Teachers: The Second Parents of Students. Journal of Educational Review Faculty of Educational in MCU, 4(1), 1-7. Retrieved from https://so02.tci-thaijo.org/index.php/EDMCU/article/view/143782/106391

Prai-ngam, B., Benjakul, S., \& Kittipichai, W. (2019). Predicting Factors the Provision of Smoking Cessation Services among Dentists. Journal of Public Health, 49(1), 81-94. Retrieved from https://www.ph.mahidol.ac.th/thjph/journal/49_1/07.pdf

Prasantree, T. (2012). Teacher Developing Models of Students in Nakhon Phanom University. Nakhon Phanom University Journal, 2(3), 25-32. Retrieved from https://so03.tci-thaijo.org/index.php/npuj/article/view/54446

Siamrath Online. (2020). Award "Good teachers-good schools without all vices". Retrieved from https://siamrath.co.th/n/127078

Walton, K., Gentzke, A. S., Murphy-Hoefer, R., Kenemer, B., \& Neff, L. J. (2020). Exposure to Secondhand Smoke in Homes and Vehicles Among US Youths, United States, 2011-2019. Preventing Chronic Disease, 17. https://doi.org/10.5888/pcd17.200107

WorkpointTODAY online. (2021). Sor. Kho. Good teacher's activities. No vices on Teacher's Day 2021. Retrieved from https://workpointtoday.com/160121-2/

Yeepoo, C., Usa Kongthong, U., \& Sriherun, B. (2018). The development of a learning activity model for reducing and stop smoking behavior of drug addition for children and adolescent patients. Valaya Alongkorn Review (Humanities and Social Science), 8(1). 131-146. Retrieved from http://acad.vru.ac.th/Journal/journal\%208_1/8_1_10.pdf

\section{Copyrights}

Copyright for this article is retained by the author(s), with first publication rights granted to the journal.

This is an open-access article distributed under the terms and conditions of the Creative Commons Attribution license (http://creativecommons.org/licenses/by/4.0/). 